\title{
UMA ABORDAGEM SOBRE A LICENÇA PATERNIDADE*
}

\author{
Fanny Sarfati** \\ Sonia Maria Junqueira Vasconcelos de Oliveira*** \\ Luiza Akiko Komura Hoga *** \\ Regina Lucia da Silva Rodrigues****
}

SARFATI, F. et al; Uma abordagem sobre a licença paternidade. Rev. Esc. Enf. USP, v. 26, n. 3, p. $\quad-\quad$, dez., 1992.

Este estudo teve como objetivo verificar o conhecimento e aproveitamento da população com relação a licença paternidade, analisando, igualmente, a forma de participação do pai junto ao binômio mãe-filho durante o beneficio, além da identificação das necessidades da população quanto d̀ sua existência e duração.

UNITERMOS: Legislação. Licença paternidade. Relações pais-filho.

\section{Introduçăo}

As funções femininas e masculinas, dentro da estrutura familiar, têm sofrido alterações através da evolução histórica das sociedades.

BACH(2) afirma que a acentuada separação entre o campo de atuação e os papéis relacionados ao sexo, corresponde a um estágio evolutivo inferior mais próximo ao hermetismo tribal. DICKSTEIN(5) estabelece que nestas circunstâncias fica reservado à mãe, o papel de guia das relações afetivas dos filhos, e ao pai o apoio às necessidades maternas de segurança física e econômica.

Com a liberalização da mulher e sua participação crescente no mercado de trabalho, passando a exercer atividades fora de casa, deixando de assumir integralmente o seu papel social tradicional, começa a ter muita importância na unidade matrimonial a colaboraçāo recíproca, onde tudo passa a ser feito em comum. A repartição meticulosa de funções passa a não ter tanto sentido, mas ajuda a fazer com que os esforços tenham um fim comum. Nesse sentido, ARRUDA(1) comenta que um dos sinais evidentes da tendência de transformação do homem sobre terrenos considerados exclusivamente femininos, é a sua participação nas reuniões de escolas assim como em consultas ao pediatra.

\footnotetext{
- Trabalho apresentado como um dos requisitos para conclusão do curso de habilitação em Enfermagem Obstétrica (USP), 1990.

* Enfermeira Obstétrica do Hospital Universitário (USP).

** Enfermeiras Obstétricas. Mestres em Enfermagem. Assistentes do Departamento de Enfermagem Materno-Infantil e Psiquiátrica da EEUSP. Orientadoras do trabalho.

*** Enfermeira Obstétrica. Hospital Osvaldo Cruz.
} 
DICKSTEIN(5) observa que a rotura frequente de laços familiares que atinge fortemente o vínculo pais-filhos, permite perceber que a mãe não é insubstituível e que outras pessoas podem interagir construtivamente. Destaca também a importância de alguns papéis específicos, já bem determinados na sexualidade, sociabilização, moralidade e escolaridade. Por esta observação nota-se que a posição do pai pode ser concebida diferentemente.

$\mathrm{BACH}(2)$ salienta que, a rigor, não há uma atividades social ou familiar que não possa ser executada por um ou outro sexo. A ressonância psicológica e o modo de execução talvez não sejam iguais, contudo a repercussão social será mais positiva do que o resultado hipócrita da atual divisão de funções.

Segundo DICKSTEIN(5) e ROSENBLUTH(10), não há dúvidas de que, no começo, a mãe é a pessoa mais importante para o bebê, e é ela que reune a maior soma de possibilidades para a perfeita ligação efetiva com o filho, elemento fundamental na estruturação da afetividade do ser humano. $O$ pai realmente só assume uma importância direta, quando o bebê tem um pouco mais de idade. No entanto, sua presença é desejável e vantajosa para o lactente. É interessante observar como logo os bebês parecem dar-se conta dos pais também. Portanto este tem uma enorme importância para o bebê indiretamente, principalmente nas primeiras semanas, na fase de adaptação, quando a mãe e o recém-nascido (RN) necessitam de seu apoio.

De acordo com MAGANO(7), pela Organização Internacional do Trabalho, as mesmas responsabilidades devem ser divididas entre os conjuges, a fim de que nenhum sofra discriminação e, segundo a Lei Italiana 903, de 09/12/77, confere-se o direito alternativamente aos dois genitores, de se ausentarem do trabalho para cuidar dos filhos. Verifica-se a existência de uma "tendência doutrinária moderna, no sentido de rever o papel do homem no seio da família, de modo que os cónjuges conciliem harmoniosamente a atividade profissional e as responsabilidades familiares".

É neste momento que entra a grande necessidade e importância da licença paternidade.

A atual Constituição Federal diversamente da Carta Magna de 1969, prevê a licença paternidade, concedendo ao pai da criança cinco dias de licença, a partir do nascimento do seu filho.

A referida licença tem por finalidade permitir a companhia do pai junto ao bebê e da mãe, ocasiâo em que ambos se recuperam do trabalho de parto. Da mesma forma, uma licença com duração determinada, possibilita uma melhor adaptação da família à nova situação de fato, que se formou com o nascimento do filho. Trata-se de um Ato da Disposição Constitucional Transitória, artigo 10, parágrafo 1, que estabelece: "Até que a lei venha disciplinar o disposto no art. 70, XIX, da Constituição, o prazo de licença paternidade a que se refere o inciso é de cinco dias" BRASIL(4) e MAGANO(7) completa ainda que o aparato da seguridade só se tornará eficaz depois de cumpridas as fases de apresentação do programa de organização (6 meses), apreciação do programa no congresso (6 meses), além de sua implantaçăo progressiva (18 meses).

O levantamento bibliográfico realizado mostra que o tema em estudo é pouco explorado, talvez por ser recente. 
Tendo-se em vista a importância do pai, e sua participação no período perinatal, sentiu-se necessidade de realizar um estudo que demonstrasse de que forma a prorrogação da licença paternidade refletiu nas atividades exercidas pelos pais durante essa fase. Além disso, teve-se o propósito de avaliar também, o quanto a população conhece o direito à licença, e como esta está sendo usufruída.

\section{OB.JETIVOS}

1) Verificar o conhecimento e o usufruto da populaçăo com relação à licença paternidade;

2) Verificar a forma de participação do pai no período de licença paternidade;

3) Identificar as necessidades da populaçăo com relação à existência e duração da licença paternidade.

\section{MÉTODO E MATERIAL}

\section{LOCAL}

O estudo foi realizado no ambulatório de um hospital escola, onde a conduta hospitalar estabelece a rotina de uma consulta de enfermagem (de retorno) ao binómio mãe-filho no $10^{\circ}$ dia após o parto, realizada pelas enfermeiras da unidade de alojamento-conjunto (A.C.). Foi realizado neste período a fim de que a puérpera pudesse ter um tempo suficiente para vivenciar a experiência do usufruto da licença paternidade.

\section{POPUlaÇão}

A população deste estudo foi constituída por 30 puérperas que compareceram à consulta de enfermagem, conforme estabelecido e agendado pela instituição, no período de 14/09/90 a 14/10/90.

\section{CRITÉRIOS PARA SELEÇÃO dA POPULAÇÃo}

Foram incluídas puérperas que atendessem aos seguintes critérios:

a) Morar com o pai do RN, o qual deveria estar empregado e registrado em carteira; 
b) Que o binómio mãe-filho não tivesse tido intercorrências obstétricas ou neonatais, pois, caso o período de internação se prolongasse, haveria dificuldades para a participação do pai nos cuidados com o RN.

\section{INSTRUMENTO PARA COLETA DE DADOS}

Inicialmente, foram elaborados dois formulários: um para o pai da criança e outro para a puérpera. O primeiro, constituído por sete ítens de identificação, dois de convivência familiar, além de oito ítens voltados especificamente para o problema em estudo. O segundo, composto por seis dados de identificação, dois sobre a convivência familiar e sete referentes a dados obstétricos e estrutura familiar. Além destes, havia oito questōes especificas sobre o problema em estudo.

$O$ instrumento utilizado foi composto de duas partes. A primeira, constituída de itens referentes a identificação da mãe, pai e casal, incluía itens para obtenção de dados referentes ao parto, trabalho do pai, assim como tipo de união, seu tempo, $n$ o de filhos e constituição familiar. A segunda parte, composta pela entrevista propriamente dita, continha questóes semi estruturadas. Através desse instrumento, levantaram-se dados sobre o planejamento da gravidez, as atividades exercidas pelo pai durante o período de internação da puérpera e licença paternidade, a opinião do casal em relação a atuação do pai nas atividades caseiras e cuidados com os filhos, o conhecimento a respeito da licença (definição e duração), o seu usufruto, o auxílio à puérpera por alguém além do pai após a alta, bem como possibilitou-se a feitura de sugestões e comentários.

\section{TÉCNICA PARA COLETA dOS DADOS}

A coleta de dados foi realizada pelas próprias pesquisadoras, após uma apresentação às puérperas com relação a nome, categoria profissional e objetivos do trabalho, alem da garantia do sigilo das respostas.

As informações referidas pelas mães foram anotadas durante a entrevista.

\section{TRATAMENTO DOS DADOS}

Os dados referentes à parte I do formulário foram analisados segundo a freqüência absoluta e o percentual, e as questões semi estruturadas da parte II do formulário foram agrupadas de acordo com as suas semelhanças, considerando-se as justificativas para cada questão.

\section{RESULTADOS E COMENTÁRIOS}

A população deste estudo foi constituída de 30 casais (puérperas e pai do $\mathrm{RN}$ ), sendo que a faixa etária materna variou de 16 a 35 anos, sendo que 12 
$(40,0 \%)$ estavam com idade entre 16 a 20 anos. A idade paterna, variou de 18 a 45 anos, sendo que a maior freqüência, 11 (36.7\%) estava entre 21 a 25 anos, seguido de $10(33,3 \%)$ que tinham entre 26 a 30 anos.

Quanto ao tipo de união, pôde-se encontrar duas variedades: os casados legalmente e os que apenas moravam juntos, sendo que a maioria $19(63,4 \%)$ incluiam-se na segunda situação. $O$ tempo de união do casal variou de 3 meses a 17 anos, tendo-se destacado em maior freqüência $13(43,3 \%)$ de 1 a 3 anos.

A escolaridade dos casais entrevistados apresentou uma variação de analfabeto até $2^{\circ}$ grau completo. Verificou-se que a maioria da população de puérperas e pais, apresentavam $1^{\circ}$ grau incompleto, respectivamente com $22(73,2 \%)$ e $20(66,7 \%)$.

De acordo com a divisão de FONSECA(6), apresentam-se no Nivel I pessoas com cargos de ocupação manual não especializada; no Nivel II, aquelas com cargos de ocupação manual especializada, e no Nível III, cargos de supervisão e outras ocupações não manuais.

TABELA 1. Caracterização do casal, segundo o nível ocupacional. São Paulo, 1990.

\begin{tabular}{|c|c|c|c|c|}
\hline \multirow{2}{*}{ Nivel Ocupacional * } & \multicolumn{2}{|c|}{ máe } & \multicolumn{2}{|c|}{ pai } \\
\hline & no & $\%$ & no & $\%$ \\
\hline I & 27 & 90,0 & 7 & 23,3 \\
\hline II & 1 & 3,3 & 18 & 60,0 \\
\hline III & 2 & 6,7 & 5 & 16,7 \\
\hline Total & 30 & 100,0 & 30 & 100,0 \\
\hline
\end{tabular}

- Classificação do nfvel ocupacional segundo FONSECA(6).

Nota-se, na Tabela 1, que $27(90,0 \%)$ das mães apresentavam-se no Nível I de ocupação e $18(60,0 \%)$ dos pais incluíam-se no Nível II.

Quanto ao tempo de emprego no mesmo local, $15(50,0 \%)$ dos pais estavam trabalhando há menos de um ano. De certa forma, isso demonstra a alta rotatividade no trabalho dessas pessoas.

Os dados relativos aos antecendentes obstétricos e pessoais mostram que $13(43,3 \%)$ das puérperas eram primigestas e $18(60,0 \%)$ năo tinham planejado a gravidez, dado este que merece a atenção dos serviços de saúde e educacionais para melhor assistência nesta área, a fim de que se possa evitar a ocorrência de gravidez indesejada e suas conseqüências. 
Segundo MALDONADO(9), o lugar que o bebê ocupará na família vai depender, principalmente, dos fatores referentes à historia dos pais e das circunstâncias em que ocorreu a gravidez. Assim, o fato de não ter sido planejada a gravidez poderia vir a interferir no interesse e na disponibilidade dos pais em relação aos bebês.

Verificou-se, também, que $13(43,3 \%)$ dos casais tinham apenas um filho, sendo este o proprio $R N$.

TABELA 2. Opinião do pai, relatada pela mãe, quanto a sua participação nas tarefas caseiras e no cuidado com os filhos. São Paulo, 1990.

\begin{tabular}{c|c|c}
\hline Opiniāo & no & $\%$ \\
\hline Favorável & 12 & \\
faz sem reclamação & 8 & 40,0 \\
gosta & 3 & 26,6 \\
acha que é obrigação & 2 & 10,0 \\
acha importante & 2 & 6,7 \\
faz com reciamação & 27 & 6,7 \\
Subtotal & 3 & 10,0 \\
Desfavorável & & 10,0 \\
é coisa de mulher & 30 & 10,0 \\
\hline
\end{tabular}

De acordo com a tabela 2, nota-se que a maioria, 27 (90,0\%), é favorável a sua participação nas tarefas caseiras e no cuidado com os filhos, e que apenas três $(10,0 \%)$ se manifestaram contra essa participação. Dentre os favoráveis, verifica-se que a justificativa mais freqüente é que "o pai faz sem reclamar", justificativa essa que aparece em $12(40,0 \%)$ dos relatos.

Este dado mostra um elemento cultural das mulheres, o de considerar as tarefas do lar e cuidado com os filhos, como um atributo preponderantemente feminino, e a ajuda do homem nestas atividades é vista quase como "um favor". Observa-se também, que para os pais com opinião desfavorável, o argumento de que "é coisa de mulher".

Vale a pena ressaltar que, para esta população pesquisada um terço dos pais referiram gostar de participar das tarefas caseiras e do cuidado com os filhos e tamberm, consideraram importante estas atividades. Segundo ARRUDA(1) consolida-se a tendência de os pais darem aos filhos o afeto e o carinho dispensados pelas mães. 
Para BACH(2) e BALY(3), é conveniente aos homens considerarem que "lugar de mulher é em casa", não estando de acordo com a psicologia ou ideologia da mulher. Existe, também um papel definido que se espera seja desempenhado: o da esposa, mãe e dona de casa.

ROSENBLUTH(10) afirma que "alguns homens não conseguem ficar absorvidos pelo minúsculo bebé". Completa ainda que em nossa sociedade, verifica-se que os homens consideram afeminado interessar-se demais pelo RN, e então fingem falta de interesse.

TABELA 3. Opiniāo da mãe, quanto a participação do pai nas tarefas caseiras e cuidados com os filhos. São Paulo, 1990.

\begin{tabular}{l|r|r}
\hline Opiniåo da mãe & $\mathrm{n}^{\circ}$ & $\%$ \\
\hline Favoravel & 15 & 50,0 \\
bom & 6 & 20,0 \\
importante & 3 & 10,0 \\
acha que é obrigação & 2 & 6,7 \\
otimo & 2 & 6,7 \\
gosta da ajuda & 1 & 3,3 \\
acha normal & 29 & 96,7 \\
Subtotal & 1 & 3,3 \\
Desfavorável & & 100,0 \\
o homem atrapalha & 30 & \\
\hline
\end{tabular}

Nota-se na Tabela 3 que a maioria, $29(96,7 \%)$, das mães foram favoráveis à participação do pai nas tarefas caseiras e nos cuidados com os filhos. Destas, 15 $(50,0 \%)$ justificaram como sendo bom. Destaca-se que apenas uma foi desfavorável, alegando que "acha que o homem só atrapalha, não gosta que ajude a cuidar do bebê, só quando está chorando".

Talvez esta condição seja um reflexo de uma sociedade machista em que esta puérpera está inserida, sendo a acomodação uma característica relevante neste caso.

Na Tabela 4 constata-se que $20(66,6 \%)$ companheiros usufruiram da licença paternidade apesar de somente $18(60,0 \%)$ puérperas conhecerem a referida licença. Cabe salientar que durante a entrevista $12(40,0 \%)$ puérperas referiram não conhecer o termo licença paternidade, sendo que após serem orientadas, elas referiram que $7(23,3 \%)$ de seus companheiros haviam tido a licença. 
TABELA 4. Conhecimento e ususfruto da licença paternidade. São Paulo, 1990.

\begin{tabular}{|c|c|c|c|c|c|c|}
\hline \multirow{3}{*}{ Usufruto } & \multicolumn{4}{|c|}{ Conhecimento } & & \\
\hline & \multicolumn{2}{|c|}{$\operatorname{sim}$} & \multicolumn{2}{|c|}{ não } & \multicolumn{2}{|c|}{ Total } \\
\hline & $n^{2}$ & $\%$ & ne & $\%$ & $n^{2}$ & $\%$ \\
\hline $\operatorname{sim}$ & 13 & 43,3 & 7 & 23,3 & 20 & 66,6 \\
\hline กร์o & 5 & 16,7 & 5 & 16,7 & 10 & 33,4 \\
\hline Total & 18 & 60,0 & 12 & 40,0 & 30 & 100,0 \\
\hline
\end{tabular}

Cerca de um terço da população (10 pais) não teve a licença paternidade nos moldes determinados pela Consitutuição da Repáblica Federativa do Brasil de 1988 (ou seja, pelo prazo de cinco dias). Desses, seis não solicitaram a licença paternidade devido ao curto tempo de serviço que possuiam na firma em questão, associado ao medo do desemprego(4)e, também, por desconhecer o benefício(2). Três pais tiveram de um a três dias de licença paternidade e um estava de férias por ocasião do parto. Convém esclarecer que estas informações (de um a três dias) foram fornecidas pelas puérperas. Acreditamos que essas informaçōes possam estar erradas. Com efeito, pode ter ocorrido das puérperas terem considerado como início do período da licença paternidade as datas em que tiveram alta hospitalar, ou seja, 60 horas apos o nascimento da criança, ao passo que, na verdade, seus companheiros já estariam gozando o benefício desde a data do parto, como, aliás, exige a lei. Portanto, quando as puérperas referem que o período da licença usufruido foi de um a três dias, pode-sę concluir que, na realidade, o período foi de um ou cinco dias, ou seja, ou nos moldes da legislaçáo anterior ou na conformidade da atual Constituição Federal.

TABELA 5. Época do usufruto da licença paternidade. São Paulo, 1990.

\begin{tabular}{l|c|c}
\hline Época & $\mathrm{n}^{8}$ & $\%$ \\
\hline Dia do nascimento & 10 & 50,0 \\
Depois do nascimento & 8 & 40,0 \\
Antes do nascimento & 1 & 5,0 \\
Nåo sabe referir & 1 & 5,0 \\
\hline Total & 20 & 100,0 \\
\hline
\end{tabular}


Dentre os 20 pais que sairam de licença, $10(50,0 \%)$ gozaram-na a partir da data do nascimento do RN (Tabela 5), tal como estabelece a Constituiçăo Federal. Os dados das Tabelas 4 e 5 mostram que estes direitos concedidos pela Constituição promulgada, e amplamente divulgada pelos meios de comunicaçăo, são conhecidos pela maioria desta população $(60,0 \%)$ e está sendo cumprida pelos empregadores, visto que $7,(23,3 \%)$ embora não cientes do direito, usufruíram da licença paternidade (Tabela 4).

O Quadro 1 refere-se a atividades desenvolvidas pelo pai durante a licença paternidade.

\begin{tabular}{|l|c|c|}
\hline Quadro 1. Atividades desenvolvidas pelos 20 pais durante a licença paternidade \\
São Paulo, 1990. \\
\hline Atividades & $\mathrm{n}^{2}$ & $\%$ \\
\hline Visitas à mãe & 20 & 37,0 \\
Tarefas caseiras & 12 & 22,2 \\
Registro do RN & 11 & 20,4 \\
Cuidados com os filhos & 5 & 9,3 \\
Compras & 4 & 7,4 \\
Cuidados com o RN & 2 & 3,7 \\
\hline Total & $54^{*}$ & 100,0 \\
\hline
\end{tabular}

- Os pais exerceram uma ou mais atividades.

Observa-se no Quadro 1 que 20 (37,0\%) dos pais, visitaram suas companheiras no hospital. Além disso, é importante citar que a $12(22,2 \%)$ referiram ajudar nas tarefas caseiras, dentre elas: arrumar a casa, fazer comida, lavar roupa e montar berço, carrinho, entre outras.

Apenas duas $(3,7 \%)$ disseram ter participado dos cuidados com o RN. De acordo com MALDONADO(8), "muitos homens sentem medo de pegar o RN no colo, por ser molinho, a moleira no alto da cabeça do bebê é também algo que suscita muitos temores".

ROSENBLUTH(10) alega que o pai pode retirar-se da situaçăo por sentimentos de ciúme e inveja.

Cabe ainda ressaltar que atividades como por exemplo: visitas à mãe e registros do RN, foram executadas pelo pai independentemente do mesmo ter a licença paternidade ou não. As atividades desenvolvidas pelo pai como: cuidados

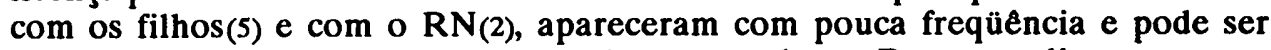
atribuído ao fato de não fazer parte da nossa cultura. Deve-se salientar que na população estudada, $43,3 \%$ eram primigestas, pressupondo-se portanto que não 
havia outras crianças em casa. Além disso, pela rotina hospitalar, o tempo mínimo de internação é de 60 horas após o parto, de forma que se tudo estivesse correndo bem o RN só iria para casa por volta do 30 dia da licença paternidade. As 11 puérperas casadas referiram que seus maridos registraram seus filhos durante $o$ perfodo de licença paternidade, uma vez que para esse registro bastava apresentar a certidão de casamento, năo havendo necessidade da presença da mãe no cartório.

Verificou-se que $18(60 \%)$ dos pais participaram das tarefas caseiras e dos cuidados com o RN, espontaneamente. No entanto, $10(33,3 \%)$ participaram apenas quando solicitados. Das mulheres entrevistadas apenas duas $(6,6 \%)$ referiram que o pai não auxiliou no serviço doméstico e nos cuidados com os filhos.

Apos a alta hospitalar, 27 mulheres tiveram ajuda de outras pessoas, sendo que 23 foram auxiliadas por parentes próximos.

De acordo com as respostas dadas, observa-se que 26 puérperas foram favoráveis à existência da licença. Dentre estas, 16 consideraram sua duraçăo suficiente. Neste item, as opiniōes variaram desde boa até importante e 6 tima. As duas que se manifestaram conformadas com a existência da licença paternidade, referiram que: "uma vez que os dois trabalham, tem que ajudar um ao outro...", ou ainda "ser normal pois sempre fez assim desde o outro filho".

Vale a pena relatar o comentário de uma puérpera, que apesar de conhecer a licença paternidade, por ter tido parto gemelar, expressa a seguinte dúvida: "por terem sido dois bebês, meu companheiro năo teria direito a licença de 10 dias?".

\section{CONCLUSÕES}

O presente estudo realizado com 30 puérperas dentre as quais, $12(40,0 \%)$ estavam entre a faixa de $16-20$ anos enquanto que $11(36,7 \%)$ de seus companheiros na faixa de 21-25 anos. A escolaridade dos dois sexos era o 19 grau incompleto (22 mães $(73,2 \%$ e 20 pais $(66,7 \%))$. Quanto ao nível de ocupação, 27 mães $(90,0)$ classificaram-se no nível I e 18 pais $(60,0 \%)$ no nível II.

Nesta amostra da população:

1. 18 puérperas $(60,0 \%)$ conheciam a licença paternidade e 20 pais $(66,6 \%)$ usufruiram da mesma.

2. Durante a licença paternidade os pais exerceram uma ou mais atividades voltadas para suas famílias, verificando-se assim a real necessidade e importância da licença paternidade.

3. 26 puérperas demonstraram-se satisfeitas com a existência da licença paternidade. Dentre elas, 16 referiram estar satisfeitas com a sua duração também.

\section{CONSIDERAÇÕES FINAIS}

Uma vez que $33,4 \%$ da populaçăo pesquisada, ainda, desconhece seus direitos relativos à licença paternidade, existe uma necessidade de orientação e di- 
vulgação à população com relação aos seus direitos instituídos legalmente. Acreditamos que o melhor momento para estas orientações fossem durante as visitas da gestante ao serviço de pré-natal.

De acordo com os resultados obtidos, pode-se observar que a participaçăo do pai no cuidado direto ao RN é pequena $(3,7 \%)$. Portanto, o casal deve ser orientado, desde o pré-natal, sobre a licença paternidade e a importância da inclusão paterna na assistência ao RN, pois embora este - participação paterna reduzida - seja um valor cultural que percebemos ser dominante no nosso meio, está em vias de mudança, mesmo que lentamente. A mulher está se inserindo cada vez mais no mercado de trabalho e a divisão de trabalho masculino e feminino no domićlio tende, também, a acompanhar esta evoluçăo. Além disso, sabemos da importância de seu envolvimento no pleno desenvolvimento da criança, principalmente no âmbito psico-emocional.

Cabe verificar, por meio de um estudo, os motivos que levam o homem a não dar cuidado direto ao filhos e como a mulher e o proprio homem vivenciam esta prática atualmente, assim como há necessidade de se verificar quais são os anseios dos pais em relaçăo à manutenção ou às mudanças de papéis no contexto familiar.

Considerando que o número de puérperas insatisfeitas com a duraçăo da licença paternidade atual (5 dias) é significativo, faz-se necessária a realizaçáo de um estudo que investigue os motivos que as levaram a sentir necessidade de uma prorrogação da mesma.

SARFATI, F. et al; A broaching about paternity licence. Rev. Esc. Enf. USP, v. 26, n. 3, p. - , dez, 1992.

This study has an aim to verify the knowledge and advantage of the population with relation to paternity licence, analysing equally the form of participation of the father joined to binomial mother-child during the benefit, beside the identification of the needs of the population as much as to its existence and duration.

UNITERMOS: Legislation. Paternity licence. Parent-child relations.

\section{REFERENCIAS BIBLIOGRÁFICAS}

1. ARRUDA, R. Homens mudam para dar afeto a filhos. Estado de São Paulo, Săo Paulo, 28 abr., 1991.

2. BACH, J. M. O futuro da família: tendencias e perspectivas. Petropolis, Vozes, 1983, cap. 4, p. 38-43: Estruturas e funç̋̈es.

3. BLAY, E. A. Trabalho industrial $X$ trabalho doméstico: a ideologia no trabalho feminino. Cad. Pesq. n' 15, p. 8-17, 1975.

4. BRASIL. Constituição, 1988. Constituiçāo da República Federativa do Brasil, 1988. Sæ̋o Paulo, Ed. Revista dos Tribunais, 1989.

5. DICKSTEIN, J. O papel do pai. In: FONTES, J. A. S. Perinatologia social. Sáo Paulo, Fundo Editorial Byk-Procienx, 1984. cap. 6, p. 51-2.

6. FONSECA, G. T. Modelo para uma classificaçäo de ocupações. Rev. Bras. Est. Pedag., v.47 n² 106, p. 274-312, 1967. 
7. MAGANO, O. B. A licença paternidade. Folha de São Paulo, São Paulo, 19 out. 1988, p.B2.

8. MALDONADO, T. M. Como cuidar de bebes. 2.ed. Petropolis, Vozes, 1985. cap. 4, p.23-31: "Tenho medo de nåo saber cuidar do neném".

9. MALDONADO, T. M. Como cuidar de bebes. 2.ed. Petropolis, Vozes, 1985. cap 12, p. 85-93: o bebe e sua famflia.

10. ROSENBLUTH, D. Seu bebe. Rio de Janeiro, Imago, 1973. cap. 4, p. 42-59: Primeiros relacionamentos. 